\title{
Formulation and Properties' Evaluation of PVC/(Dioctyl Phthalate)/(Epoxidized Rubber Seed Oil) Plastigels
}

\author{
Devrim Balköse, ${ }^{1}$ Theresa O. Egbuchunam, ${ }^{2}$ Felix E. Okieimen ${ }^{3}$ \\ ${ }^{1}$ Department of Chemical Engineering, Izmir Institute of Technology, Gulbahcekoyu, Urla-Izmir, Turkey \\ ${ }^{2}$ Department of Chemistry, College of Education, Warri, Nigeria \\ ${ }^{3}$ Department of Chemistry, Centre for Biomaterials Research, University of Benin, Benin City, Nigeria
}

\begin{abstract}
Epoxidized rubber seed oil $(4.5 \%$ oxirane content, ERSO) was prepared by treating the oil with peracetic acid generated in situ by reacting glacial acetic acid with hydrogen peroxide. The thermal behavior of the ERSO was determined by differential scanning calorimetry. The effect of the epoxidized oil on the thermal stability of poly (vinyl chloride) (PVC) plastigels, formulated to contain dioctyl phthalate (DOP) plasticizer and various amounts of the epoxidized oil, was evaluated by using discoloration indices of the polymer samples degraded at $160^{\circ} \mathrm{C}$ for $30 \mathrm{~min}$ and thermogravimetry at a constant heating rate of $10^{\circ} \mathrm{C} / \mathrm{min}$ up to $600^{\circ} \mathrm{C}$. The thermal behavior of the ERSO was characterized by endothermic peaks at about $150^{\circ} \mathrm{C}$, which were attributed to the formation of network structures via epoxide groups, and at temperatures above $300^{\circ} \mathrm{C}$, which were due to the decomposition of the material. Up to $50 \%$ of the DOP plasticizer in the PVC plastisol formulation could be substituted by ERSO without a marked deleterious effect on the consistency of the plastigel formed. In the presence of the epoxidized oil, PVC plastigel samples showed a marked reduction in discoloration and the number of conjugated double bonds, as well as high temperatures for the attainment of specific extents of degradation. These results showed that the ERSO retarded/inhibited thermal dehydrochlorination and the formation of long $(n>6)$ polyene sequences in PVC plastigels. The plasticizer efficiency/permanence of ERSO in PVC/DOP plastigels was evaluated from mechanical properties' measurements, leaching/migration tests, and water vapor permeability studies. The results showed that a large proportion of DOP could be substituted by ERSO in a PVC plastisol formulation without deleterious effects on the properties of the plastigels. J. VINYL ADDIT. TECHNOL., 14:65-72, 2008. () 2008 Society of Plastics Engineers
\end{abstract}

Correspondence to: Felix E. Okieimen; e-mail: fexokieimen@yahoo.com DOI 10.1002/vnl.20142

Published online in Wiley InterScience (www.interscience.wiley.com). (c) 2008 Society of Plastics Engineers

\section{INTRODUCTION}

Poly(vinyl chloride) (PVC) is an important technical polymer. One of the problems associated with the processing and use of PVC is its low thermal stability. At elevated temperatures well below its decomposition temperature, PVC loses $\mathrm{HCl}$ (dehydrochlorination) and becomes discolored owing to the formation of long polyene sequences. This process leads to deleterious effects on the properties of the polymer. Some of the most studied aspects of the thermal degradation of PVC have been on its prevention in a chemical sense by using heat-stabilizing additives and on the circumvention of the deleterious consequences on the polymer to which it leads [1].

Many of the studies on the thermal degradation and stabilization of PVC have been carried out on PVC powder or granules in an inert medium [2-5], even though PVC is more often used in the plasticized form (plastisol/plastigel) with the plasticizer component of the formulation exceeding 50\% [6]. The PVC plastisols are suspensions of PVC resin in a plasticizer in the presence of other additives. The industrial processing of plastisols involves heating of the plastisol in an oven at about $140-180^{\circ} \mathrm{C}$, where the plastisol undergoes gelation and fusion leading to the formation of plastigels [7]. Because, in these applications, the plasticizer molecules are intimately associated with the resin, it is important to understand the thermal behavior of PVC in the environment of the plasticizer [8]. Plasticizers are generally compounds of low to medium molecular weight (resins or liquids) with measurable vapor pressure below their boiling points, and they may, in high-temperature environments, evaporate and/or degrade with negative consequences on the properties of the plasticized material.

In our previous studies $[9,10]$, we examined the effect of epoxidized rubber seed oil (ERSO) on the thermal degradation of PVC powder by using rate measurements at 
$1 \%$ conversion to assess the effect of the additive. Several other reports $[11,12]$ on the use of epoxidized triglycerides and esters derived from them as heat-stabilizing additives for PVC claim that their effectiveness as stabilizers is related to the oxirane content and is due to the facile reactions of the epoxide with $\mathrm{HCl}$ evolved at the early stages of dehydrochlorination (which precludes autoaccelaration of the dehydrochlorination process) and with the labile chlorine atoms in the PVC (which reduces the susceptibility of the polymer to dehydrochlorination). The compatibility of epoxy compounds with PVC and the suitability of epoxidized triglycerides as biodegradable nontoxic plasticizers for PVC provide additional rationales for the examination of the effects of epoxidized triglycerides on the thermal degradation of PVC plastigels.

In this report, ERSO (4.5\% oxirane content) was substituted for dioctyl phthalate plasticizer in PVC plastisol formulations, and the thermal properties of the plastigels were examined.

\section{EXPERIMENTAL}

\section{Materials}

The PVC (Petvinil P.38/74, $\overline{M_{v}}$ 50,000) was used without further purification. Dioctyl phthalate (DOP) (Merck) (refractive index 1.4399 and density $0.993 \mathrm{~g} / \mathrm{cm}^{3}$ ) was used as the plasticizer. ERSO was prepared in our laboratory. The detailed procedure for the preparation and determination of the oxirane content of the epoxidized oil has been reported elsewhere [13].

\section{Preparation of PVC Plastigels}

The PVC plastisols were prepared by mixing adequate amounts of PVC resin and DOP with varying amounts of ERSO (Table 1). Thin films of the plastisols were prepared by using a $90-\mu \mathrm{m}$ film applicator (Sheen 113N) and then gelled for $15 \mathrm{~min}$ in an air-circulating oven (EV 018) at $140 \pm 2{ }^{\circ} \mathrm{C}$ in order to obtain the plastigels. The formulation containing $100 \%$ of ERSO did not form a homogeneous plastigel, and no further tests were carried out on this sample.

\section{Characterization of ERSO}

The thermal behavior of ERSO was studied by thermogravimetry (TGA) using a Shimadzu TGA-51 instru-

TABLE 1. Recipe for the formulation of PVC/DOP/ERSO plastisols.

\begin{tabular}{lrrrrr}
\hline${\text { Ingredients }(\mathrm{phr})^{\mathrm{a}}}^{\mathrm{a}}$ & I & II & III & IV & V \\
\hline DOP & 80 & 60 & 40 & 20 & 0 \\
ERSO & 0 & 20 & 40 & 60 & 80 \\
\hline
\end{tabular}

${ }^{\text {a}}$ Parts by weight per hundred parts of resin. ment operated under a $\mathrm{N}_{2}$ atmosphere at a heating rate of $10^{\circ} \mathrm{C} / \mathrm{min}$ up to $600^{\circ} \mathrm{C}$, and by differential scanning calorimetry (DSC) using a Shimadzu DSC-50 analyzer under a $\mathrm{N}_{2}$ atmosphere at a heating rate of $10^{\circ} \mathrm{C} / \mathrm{min}$ up to $200^{\circ} \mathrm{C}$.

\section{Thermal Stability Studies}

Static Oven Tests. Samples of the PVC plastigels were heated in an air-circulating oven at $160^{\circ} \mathrm{C}$ for $30 \mathrm{~min}$. Changes in the Yellowness Index (YI) measured by using an Avantes Spectrocam instrument and UV absorbance at $360 \mathrm{~nm}$ measured by using a Perkin-Elmer Lambda 45 UV spectrophotometer were determined before and after the heat treatment.

Thermogravimetric Studies. Thermograms of the plastigels were obtained under nitrogen by using a Shimadzu TGA-51 analyzer at a heating rate of $10^{\circ} \mathrm{C} / \mathrm{min}$.

\section{Plasticizer Efficiency and Permanence Properties}

Mechanical Properties of PVC/DOP/ERSO Plastigel Films. The mechanical properties, ultimate tensile strength, elastic modulus, and percentage elongation at break of the plastigel films were determined according to the ASTM D882 standard by using a Testomeric M500$100 \mathrm{KN}$ machine at a strain rate of $50 \mathrm{~mm} / \mathrm{min}$ at room temperature. The sheets were cut into $100 \mathrm{~mm} \times 10 \mathrm{~mm}$ strips, as measured with a digital caliper. Five determinations were made for each sample, and the average value was used for all the samples.

Leaching Test. Leaching of plasticizers from plasticized PVC samples was carried out by using the method described by Rahman and Brazel [14]. In a typical experiment, thin rectangular samples $\left(\sim 30 \times 10 \mathrm{~mm}^{2}\right)$ having weights between 0.04 and $0.07 \mathrm{~g}$ were placed in $100 \mathrm{~mL}$ of deionized water in Erlenmeyer flasks and shaken at 100 cycles per minute for 10 days. To enhance the effect of leaching so that observations could be made within a short time, the temperature of the water bath was elevated to $50^{\circ} \mathrm{C}$. Sample weights were measured daily, and changes in weight of the samples were recorded.

Migration Testing. The migration of plasticizers from plasticized to unplasticized PVC films was studied at room temperature over a two-week period. Rectangular plasticized PVC sheets of $33 \times 7 \mathrm{~mm}^{2}$ surface area, weighing between 0.03 and $0.06 \mathrm{~g}$, were sandwiched between two unplasticized PVC sheets of the same shape and kept in contact by placing them between glass microscope slides secured by binder clips. The amount of plasticizer that migrated to the unplasticized sheets was determined by gravimetry and mass balance [14]. The unplasti- 
cized PVC films in contact with the plasticized films for the test period were also studied by using UV spectrometry.

Water Vapor Permeability Test. Water vapor permeability of the PVC plastigel films was measured by using a permeation cell [15]. In a typical experiment, PVC films having a diameter of $50 \mathrm{~mm}$ were placed in the hole and sealed between two rings. After the relative humidity in the upper part of the cell reached 5\%, valves at the inlet and outlet of the permeation cell were closed, and the program was started. The temperature and relative humidity data were recorded at 10 -s intervals for at least $12 \mathrm{hr}$.

\section{RESULTS AND DISCUSSION}

\section{Characterization of ERSO}

The thermal degradation of ERSO and the phase transitions occurring during dynamic heat treatment were investigated by using TGA and DSC, and the results are shown in Figs. 1 and 2, respectively. The TGA thermograms show that ERSO is stable to heat at temperatures up to $200^{\circ} \mathrm{C}$, showing less than $1 \%$ weight loss. However, at temperatures higher than $300^{\circ} \mathrm{C}$, weight loss of up to $60 \%$ is observed, owing to decomposition of the oil. It can be seen from Fig. 2 that a phase transition occurred between 150 and $170^{\circ} \mathrm{C}$, and this was associated with the glass transition $\left(T_{\mathrm{g}}\right)$ of the network structures formed by ERSO at elevated temperature. It is suggested that on heating, ERSO forms a three-dimensional crosslinked structure via the epoxy groups with $T_{\mathrm{g}}$ around $150^{\circ} \mathrm{C}$. The endothermic peaks observed at $300^{\circ} \mathrm{C}$ and $400^{\circ} \mathrm{C}$ were attributed to decomposition and are consistent with the TGA results. These results indicate that ERSO would be useful in resin production.

\section{Thermal Stability Studies}

The discoloration of PVC measured in terms of Yellowness Index, the number and length of conjugated double bonds, evolution of $\mathrm{HCl}$ (dehydrochlorination), and

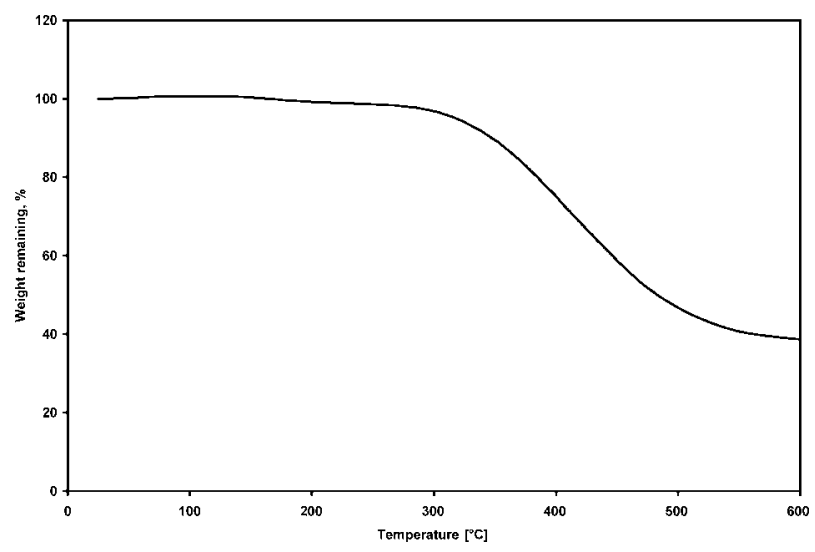

FIG. 1. TGA thermogram of epoxidized rubber seed oil.

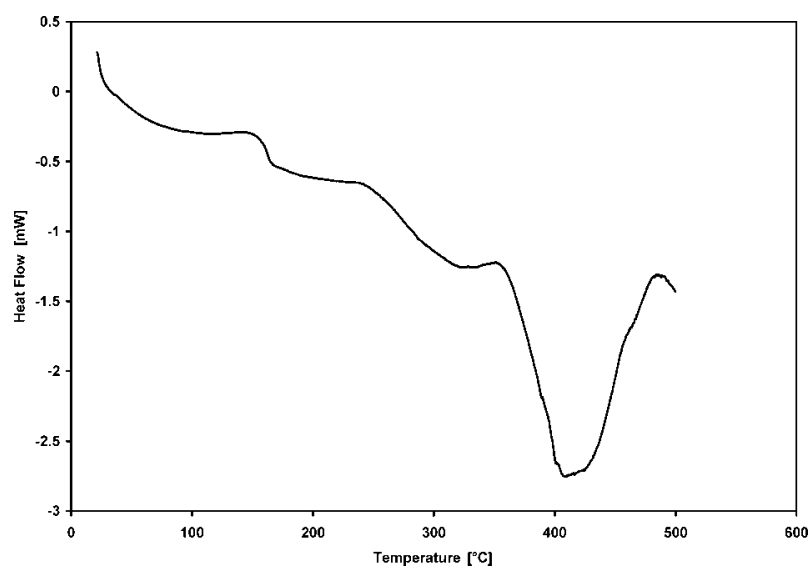

FIG. 2. DSC thermogram of epoxidized rubber seed oil.

changes in the weight of the PVC upon heating are all measures of the thermal degradation of PVC.

Yellowness Index of Degraded PVC Plastigels. During dehydrochlorination, double-bond sequences are formed within the PVC polymer chains. The color of the degraded PVC is an indication of the presence of conjugated double bonds and changes from yellow to orange to brown as the number of conjugated double bonds increases. Yellowness Index (YI) of the undegraded and degraded (at $160^{\circ} \mathrm{C}$ for $30 \mathrm{~min}$ ) PVC plastigels was calculated by using the relationship [16]

$$
\mathrm{YI}=\frac{0.72 \mathrm{a}+1.79 \mathrm{~b}}{L} \times 100
$$

Here $a$ and $b$ are based on color grade (red and yellow, respectively) and $L$ on the measurement of brightness.

The changes in the values of YI (Table 2) were used as estimates of the relative thermal stability of the PVC plastigel samples; the higher the value of YI, the greater the extent of degradation of the sample. Changes in the values of Yellowness Index were found to be above 27 for the unstabilized PVC plastigel and up to 107 for the plastigel sample in which $75 \%$ of the DOP plasticizer was substituted by ERSO. These results would suggest a deleterious effect of ERSO on the thermal stability of PVC/ DOP/ERSO plastigels. However, when comparisons are made with the visual color assessment of the degraded PVC plastigels, it would appear that changes in discoloration indices have not provided a reliable assessment of

TABLE 2. Color and YI of PVC/DOP/ERSO plastigels.

\begin{tabular}{lcrc}
\hline \multirow{2}{*}{$\begin{array}{l}\text { Additive } \\
(\% \text { ERSO) }\end{array}$} & Undegraded & Degraded & $\begin{array}{c}\text { Yolor } \\
\text { degraded }\end{array}$ \\
\cline { 2 - 3 } 0 & 4.23 & 31.95 & Light brown \\
25 & 5.36 & 39.23 & Light yellow \\
50 & 5.36 & 56.12 & Yellow \\
75 & 5.25 & 111.12 & Dark yellow \\
\hline
\end{tabular}




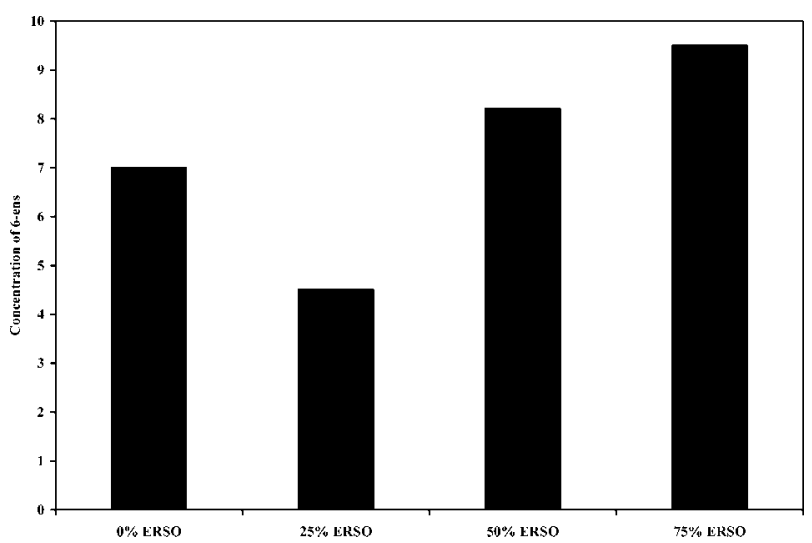

FIG. 3. UV absorbance at $360 \mathrm{~nm}$ of PVC/DOP/ERSO plastigels degraded at $160^{\circ} \mathrm{C}$ for $30 \mathrm{~min}$.

the extent of thermal degradation of the PVC/DOP plastigel and the effect of ERSO on the degradation process.

UV Studies of Degraded PVC Plastisol Samples. The UV absorbance at $360 \mathrm{~nm}$ of the degraded PVC plastigels

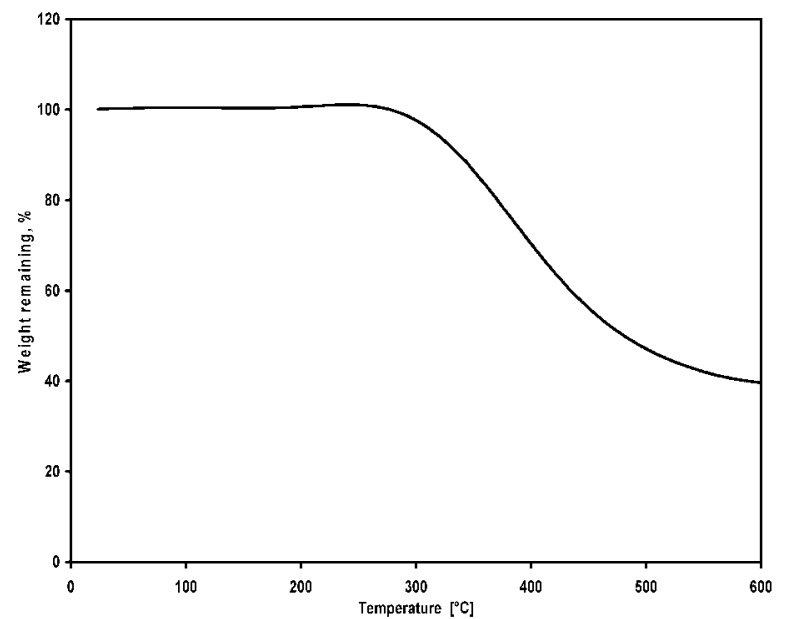

(a)

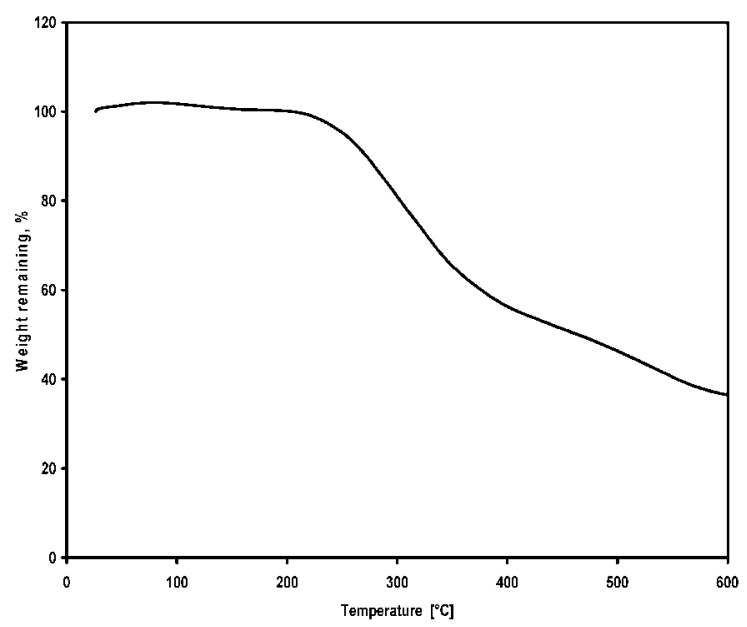

(c) was used to estimate the concentration of polyene sequences with six conjugated double bonds in the degraded polymer chain. The results (see Fig. 3) show that the plastigel sample containing $25 \%$ of ERSO showed the lowest concentration of these polyene sequences. The stabilizing effect of epoxy compounds on the degradation of PVC is known to be dependent on the oxirane content of the compound. The observed increased susceptibility to degradation of the PVC plastigels containing relatively high levels of ERSO ( $\geq 50 \%)$ is thought to be due to the thermal behavior of ERSO. At elevated temperatures, ERSO loses its fluidity and forms three-dimensional structures leading to incompatibility and phase separation from DOP. The higher the level of ERSO in the plasticizer mixture, the greater the heterogeneous regimen of the ERSO/DOP mixture, with implications on the stabilizing effect.

\section{Thermogravimetric Studies}

The macroscopic phenomenon that is associated with the thermal degradation of PVC plastigel is loss of mass resulting from dehydrochlorination and plasticizer evapo-

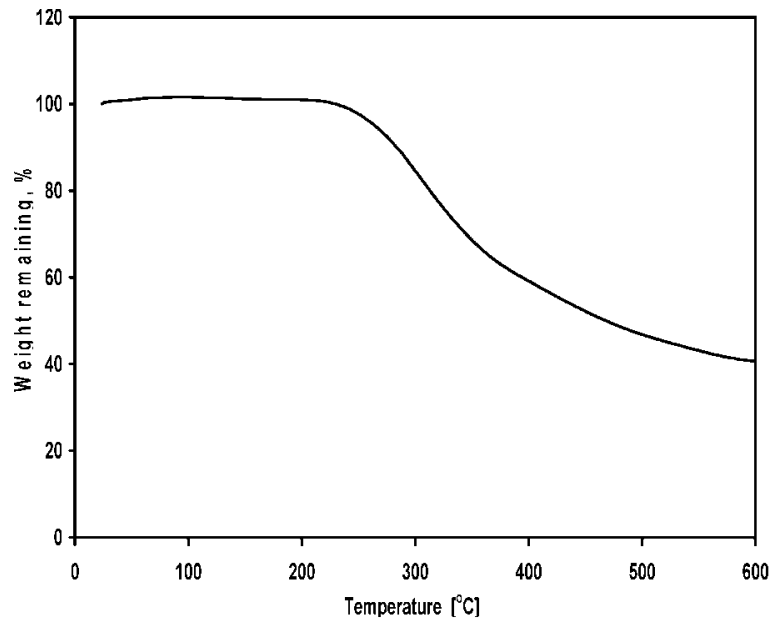

(b)

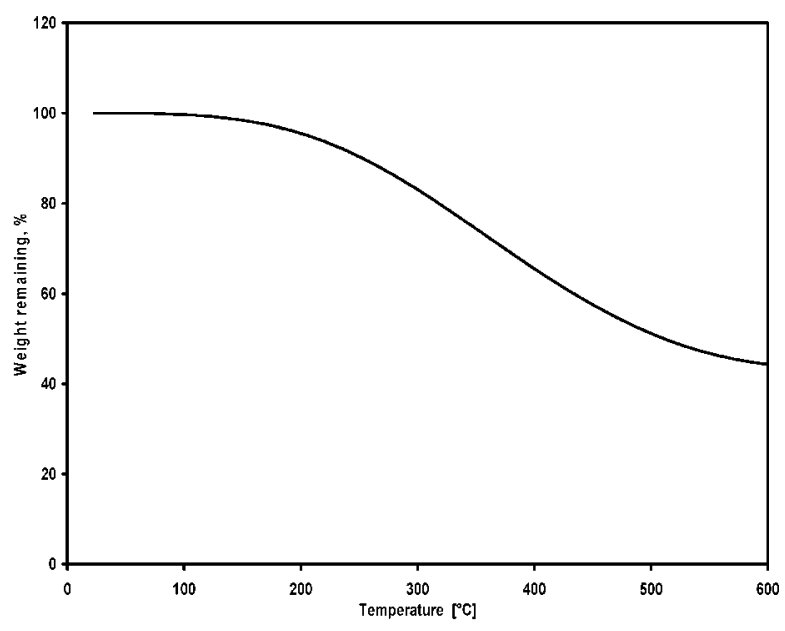

(d)

FIG. 4. Thermograms of PVC/DOP/ERSO plastigels containing (a) $0 \%$ ERSO, (b) 25\% ERSO, (c) 50\% ERSO, and (d) $75 \%$ ERSO. 
TABLE 3. Effect of ERSO on the thermal stability of PVC/DOP plastigels.

\begin{tabular}{|c|c|c|c|c|c|}
\hline \multirow{2}{*}{$\begin{array}{l}\text { Sample } \\
\text { (\% ERSO) }\end{array}$} & \multirow[b]{2}{*}{ Temp. of onset decomp. $\left({ }^{\circ} \mathrm{C}\right)$} & \multicolumn{3}{|c|}{$\begin{array}{l}\text { Temperature at which various extents of } \\
\text { degradation were attained }\left({ }^{\circ} \mathrm{C}\right)\end{array}$} & \multirow[b]{2}{*}{ Residual wt $\%$ at $600^{\circ} \mathrm{C}$} \\
\hline & & $10 \%$ & $30 \%$ & $50 \%$ & \\
\hline 0 & 302 & 337.20 & 401.30 & 480.20 & 39.7 \\
\hline 25 & 252 & 283.50 & 344.50 & 468.00 & 40.60 \\
\hline 50 & 238 & 271.80 & 333.10 & 463.70 & 36.50 \\
\hline 75 & 203 & 252.70 & 374.30 & 511.00 & 44.30 \\
\hline
\end{tabular}

ration [17]. Figure 4 shows the thermograms of PVC/ DOP/ERSO plastigels containing various amounts of ERSO. Previous workers showed that the degradation of PVC plastisols is a two-stage process. The initial stage corresponds to dehydrochlorination, and the second stage is related to carbonization of structures formed during the first stage of degradation and to the formation of hydrocarbons $[6,18]$.

The relative thermal stability of the PVC/DOP/ERSO plastigels is given in Table 3. The results show that the temperatures at which various extents of degradation were attained are higher for the plastigel sample containing no ERSO and tend to decrease with increases in the ERSO content of the DOP/ERSO plasticizer mixture.

In order to gain further insight into the thermal behavior of PVC/DOP/ERSO plastigels, differential scanning calorimetry (DSC) studies were carried out under a $\mathrm{N}_{2}$ atmosphere at a heating rate of $10^{\circ} \mathrm{C} / \mathrm{min}$. The transition temperature and enthalpy of decomposition of the PVC/DOP/ERSO plastigels are given in Table 4. The endothermic peaks that were associated with decomposition occurred at higher temperature for the plastigel samples containing low ERSO and brought about weight losses ranging from $16.96 \%$ for plastigel without ERSO to $29.42 \%$ for plastigel containing $50 \%$ of ERSO. The results show that although the decomposition temperatures of plastigels containing ERSO were lower than the decomposition temperature of plastigel without ERSO, the values of the enthalpy change for decomposition were higher for PVC/DOP/ERSO plastigels, and the difference in the change of enthalpy increased with the ERSO content of the plastigel.

\section{Plasticizer Efficiency/Permanence}

Mechanical Properties. Typical stress-strain plots for PVC/DOP/ERSO plastigels are shown in Fig. 5. The val-

TABLE 4. Glass transition, decomposition temperatures, and enthalpy of decomposition of PVC/DOP/ERSO plastigels.

\begin{tabular}{lcccc}
\hline $\begin{array}{l}\text { Sample } \\
(\% \text { ERSO })\end{array}$ & $\begin{array}{c}\text { Endothermic } \\
\text { peak }\left({ }^{\circ} \mathrm{C}\right)\end{array}$ & Wt loss $(\%)$ & $\Delta H(\mathrm{~J} / \mathrm{g})$ & $T_{\mathrm{g}}\left({ }^{\circ} \mathrm{C}\right)$ \\
\hline 0 & 310.07 & 16.96 & 152.43 & 76.13 \\
25 & 317.35 & 25.81 & 184.24 & 72.05 \\
50 & 316.07 & 29.42 & 292.84 & 76.17 \\
75 & 311.82 & 17.59 & 227.35 & 80.92 \\
\hline
\end{tabular}

ues of the tensile properties are given in Table 5. A plasticizer is incorporated in a polymer to reduce the modulus, tensile strength, hardness, density, melt viscosity, glass transition temperature, electrostatic chargeability, and volume resistivity of the polymer, while increasing its elongation at break, toughness, dielectric constant, and power factor [19]. The results in Table 5 show a general increase in elastic modulus with increases in the ERSO content of the plastigel, with the sample containing $75 \%$ of ERSO showing about a $280 \%$ increase in the value of the modulus. Similar initial increases in tensile strength and elongation at break with increases in ERSO content of the plastigel up to 50 and $25 \%$ of ERSO, respectively, followed by a marked decrease in the measured properties at a higher ERSO content, were observed. The increases in tensile strength and elastic modulus with ERSO content of the plasticizer may be attributed to its polarity, which increases the cohesive energy density, such that the materials tend to hold themselves together more tightly, thus resulting in reduced mobility and flexibility [20]. Based on the measured mechanical properties, these results indicate that relatively small proportions $(<50 \%)$ of a primary plasticizer, such as DOP, may be substituted by ERSO without compromising plasticizer efficiency.

Leaching of Plasticizer. Leaching tests of plasticizer from the PVC/DOP/ERSO plastigels were performed for 10 days. The weight loss of plasticizer as a function of time is shown in Fig. 6. It can be seen that all of the samples showed a considerable resistance to leaching, with a maximum weight loss within the duration of the tests of less than $7 \%$. Plastigel samples containing 0 and $25 \%$ of ERSO showed a marginal net weight gain $(\leq 4 \%)$, whereas the sample containing $75 \%$ of ERSO showed between 2 and $6 \%$ weight loss during the 10 -day test period.

Migration of Plasticizer. The migration levels of plasticizers from the PVC/DOP/ERSO plastigel sample unto unplasticized PVC films are given in Table 6 . The results show very low plasticizer migration from the plastigel samples, with the sample containing no ERSO showing the highest migration level $(0.92 \%)$. The sample containing $25 \%$ of ERSO showed $0.22 \%$ of plasticizer migration, and the sample containing $75 \%$ of ERSO showed no plasticizer migration.

Studies by UV spectrophotometry were carried out on the unplasticized PVC films used for the migration studies. The 


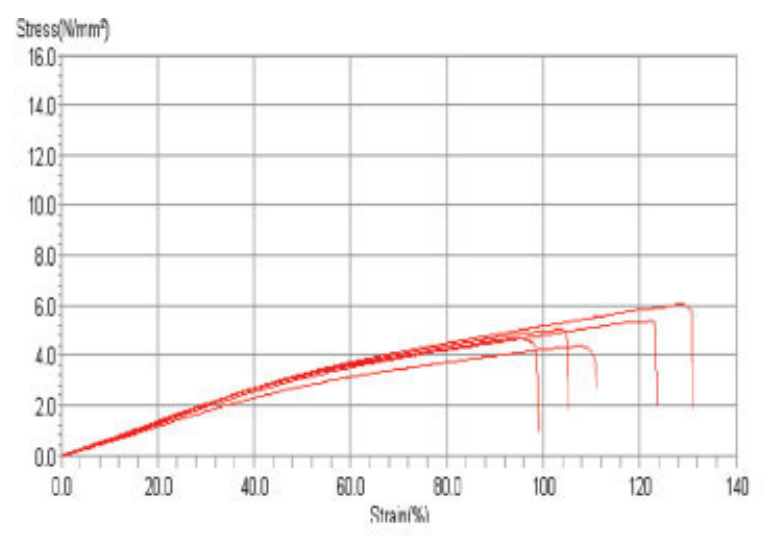

(a)

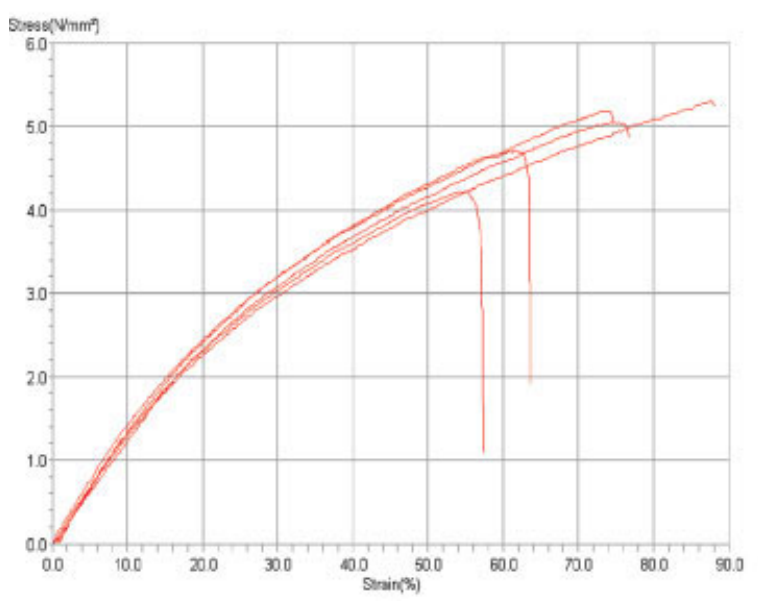

(c)

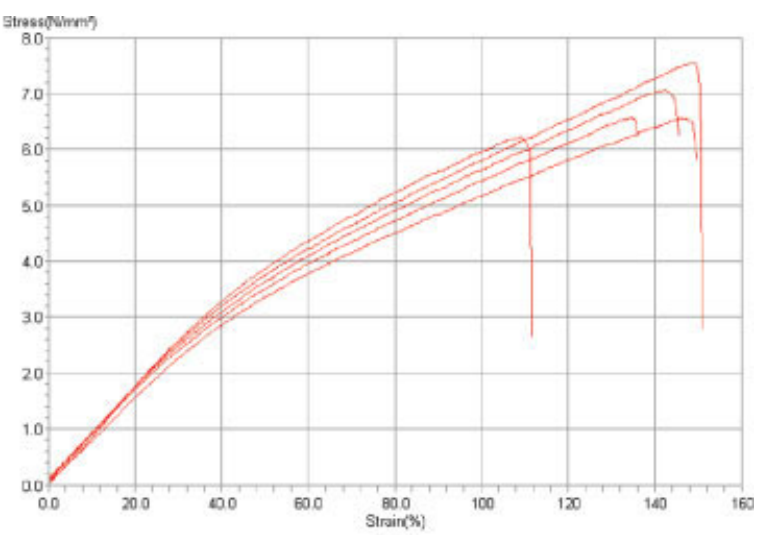

(b)

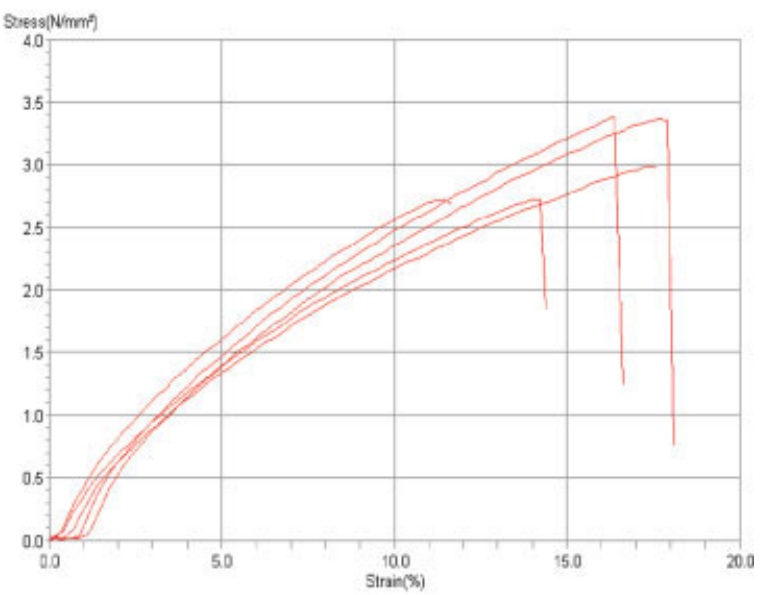

(d)

FIG. 5. Stress-strain behavior for the PVC/DOP/ERSO plastigels containing (a) 0\% ERSO, (b) 25\% ERSO, (c) 50\% ERSO, and (d) $75 \%$ ERSO. [Color figure can be viewed in the online issue, which is available at www.interscience.wiley.com.]

UV spectra (Fig. 7) showed absorption bands at 200-300 nm which were absent from the spectrum of the unplasticized film (which was cast from a solution of PVC in THF) and are assigned to DOP. They indicate that ERSO may have higher compatibility with PVC than DOP.

Leaching and migration of the plasticizers in flexible polymer products represents a major challenge in research for the plasticizer industry. Whether the plasticizer leaches out to a liquid or migrates to a gaseous or solid substance, the polymers fail to retain their flexibility, and the loss of plasticizers leaves the polymers inappropriate for the desired application [21]. In addition, the plasticizers coming out of the polymers often pose health and environmental risks [21]. The permanence properties

TABLE 5. Tensile mechanical properties of PVC/DOP/ERSO films.

\begin{tabular}{lccc}
\hline $\begin{array}{l}\text { Plasticizer } \\
\text { content (\% ERSO) }\end{array}$ & $\begin{array}{c}\text { Elastic } \\
\text { modulus }\end{array}$ & $\begin{array}{c}\text { Tensile } \\
\text { strength (KPa) }\end{array}$ & \% Elongation \\
\hline 0 & 0.064 & 21.99 & 121.74 \\
25 & 0.072 & 49.66 & 148.39 \\
50 & 0.104 & 50.60 & 79.75 \\
75 & 0.247 & 16.73 & 17.40 \\
\hline
\end{tabular}

shown by PVC/DOP/ERSO plastigels can be attributed partly to the relatively high molecular weight of ERSO and to its thermal behavior (tending to form network structures at elevated temperatures). The results from

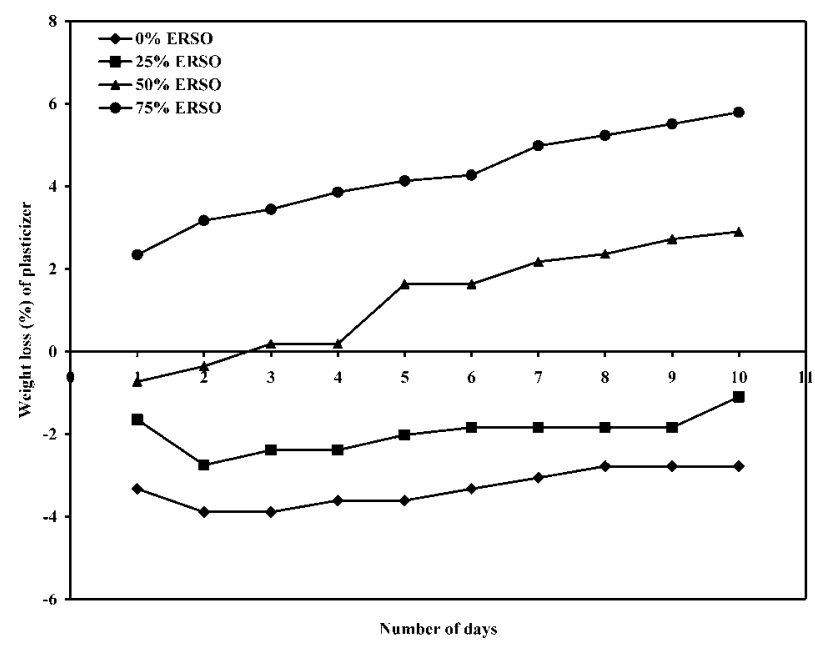

FIG. 6. Percentage of plasticizers lost due to leaching in deionized water from PVC plasticized samples at $50^{\circ} \mathrm{C}$ for 10 days. 
TABLE 6. Migration of plasticizers from plasticized to unplasticized PVC sheets.

\begin{tabular}{lc}
\hline $\begin{array}{l}\text { Plasticizer } \\
\text { content (\% ERSO) }\end{array}$ & $\begin{array}{c}\text { Percentage of } \\
\text { plasticizer migrated }\end{array}$ \\
\hline 0 & 0.92 \\
25 & 0.22 \\
50 & 0.45 \\
75 & - \\
\hline
\end{tabular}

these studies show that the permanence properties of ERSO in PVC/DOP plastisols compare favorably with those of phthalate plasticizers.

Water Vapor Permeability. Plastisols are used in various applications such as in membranes, tubes, and coil coatings etc., in which water vapor permeability is considered to be an important performance criterion. The resistance to water vapor permeation by PVC/DOP/ERSO plastigels was measured in terms of the time taken for the onset of permeation (time lag) and the permeability coefficient, which gives an assessment of the barrier property of the material.

It was found that the plastigel not containing ERSO showed the shortest time lag (17.5 $\mathrm{min})$, while the sample containing $25 \%$ of ERSO gave the longest time lag (29.5 min). Lower values of time lag, 20.5 and $26.5 \mathrm{~min}$, were obtained for samples containing 50 and $75 \%$ of ERSO, respectively. The variation of water permeability coefficient with ERSO content of the plastigels is shown in Fig. 8. The values of the permeability coefficient are generally about the same order of magnitude, increasing somewhat with ERSO content of the plastigel. These results show that the barrier (against water vapor) properties of PVC/DOP plastigels are not compromised dramatically by the incorporation of ERSO as a secondary plasticizer.

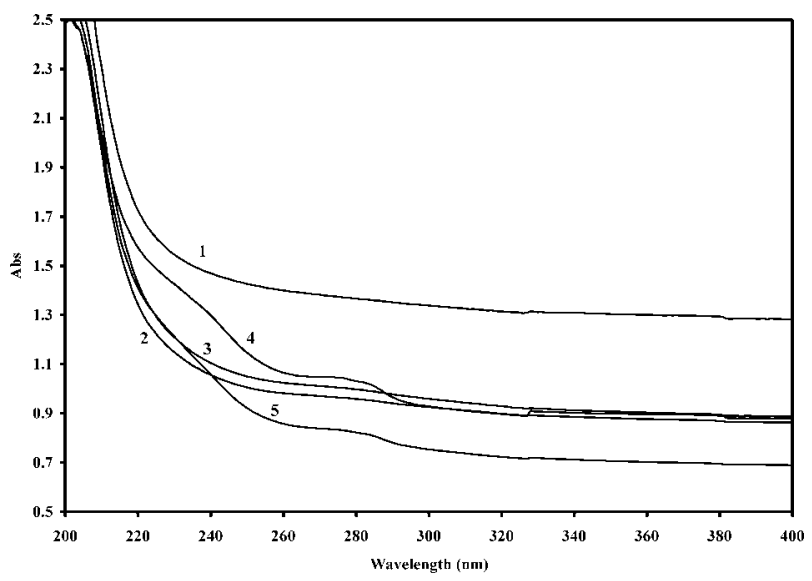

FIG. 7. UV spectra of PVC films after migration testing: (1), unplasticized PVC, (2) $0 \%$ ERSO, (3) 25\% ERSO, (4) 50\% ERSO, and (5) $75 \%$ ERSO.

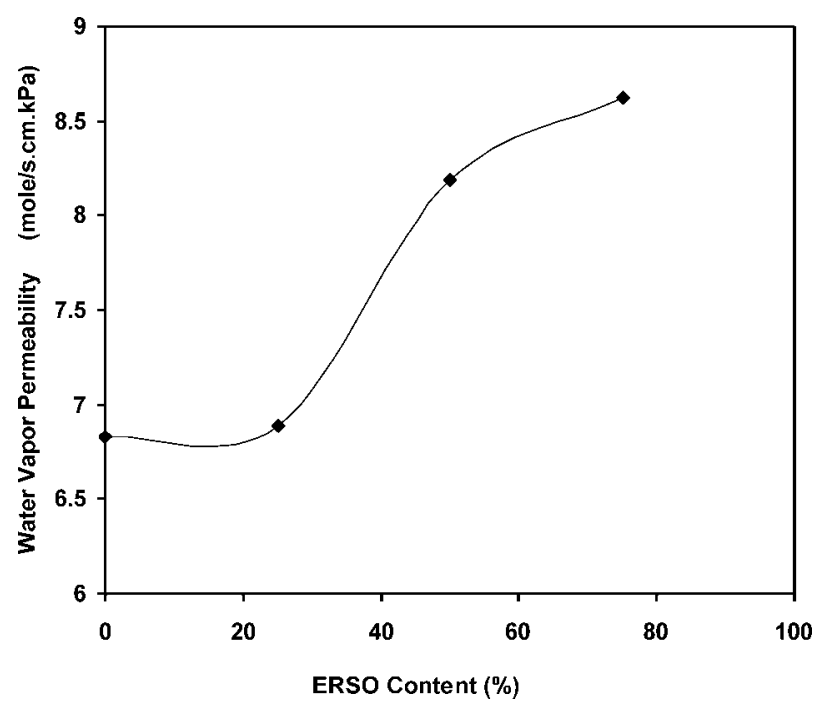

FIG. 8. Water vapor permeability of the films as a function of the ERSO content.

\section{CONCLUSION}

In this study, the effects of substituting DOP by ERSO on the mechanical, permanence, thermal, and water vapor transport properties of PVC/DOP/ERSO were studied. At low to moderate $(\leq 50 \%)$ levels of incorporation of ERSO, moderate improvements in the measured properties of the plastigels were observed. The thermal behavior of ERSO (i.e., its tendency to form network structures at elevated temperatures) appears to determine the upper limit of the effective substitution of DOP by ERSO in PVC plastisol formulations.

\section{ACKNOWLEDGMENTS}

T.O.E. is grateful to Professor Devrim Balköse, Head, Department of Chemical Engineering, Izmir Institute of Technology, for guidance and assistance during the course of some aspects of this work and to the Council and Management, College of Education, Warri, Nigeria, for a study leave.

\section{REFERENCES}

1. W.H. Starnes Jr., Prog. Polym. Sci., 27, 2133 (2002).

2. M.H. Fisch and R. Bacaloglu, Plast. Rubber Compos., 28, 119 (1994).

3. O.A. Peters, M. Turoti, and J.B. Adeniyi, Polym. Degrad. Stab., 50, 175 (1995).

4. M. Rogestedt and T. Hjertberg, Macromolecules, 26, 60 (1993).

5. K. Wajiha and A. Zahoor, Polym. Degrad. Stab., 53, 243 (1996).

6. A. Jimenez, J. Lopez, A. Iannoni, and J.M. Kenny, J. Appl. Polym. Sci., 81, 1881 (2001).

7. J.C. Garcia and A. Marcilla, Polymer 39, 3507 (1998).

8. A. Jimenez, V. Berenguer, J. Lopez, and J. Vilaplana, J. Appl. Polym. Sci., 60, 2041 (1996). 
9. F.E. Okieimen, Ind. Crops Prod, 15, 71 (2002).

10. F.E. Okieimen, J. Sci. Ind. Res., 59, 563 (2000).

11. M.T. Benaniba, N. Belhaneche-Bensemra, and G. Gelbard, Polym. Degrad. Stab., 74, 501 (2001).

12. S.D. Howell, S.R. Besto, J.A. Meltzer, P.B. Smith, and M.F. Debrey, Thermochim. Acta, 160, 207 (1990).

13. I.O. Bakare, F.E. Okieimen, and C. Pavithran, Eur. J. Lipid. Sci. Technol., 107, 330 (2005).

14. M. Rahman and C.S. Brazel Polym. Degrad. Stab., 91, 3371 (2006).

15. O. Topcuoglu, S.A. Altinkaya, and D. Balköse, Prog. Organic Coatings, 56, 269 (2006).
16. R. Benavides, A.O. Castillo, G.M. Castenado, G.M. Lopez, and G. Arias, Polym. Degrad. Stab., 73, 417 (2001).

17. A. Jimenez, J. Lopez, J. Vilaplana, and H.J. Dussel, J. Anal. Appl. Pyrol., 40/41, 201 (1997).

18. C.E. Sogbaike, F.E. Okieimen, and C.O. Eromosele, Polym. Degrad. Stab., 88, 175 (2005).

19. G. Mathews, PVC: Production, Properties and Uses, Institute of Metals, London (1996).

20. B.L. Shah and V.V. Shertukde, J. Appl. Polym. Sci., 90, 3278 (2003).

21. M. Rahman and C.S. Brazel, Prog. Polym. Sci., 29, 1223 (2004). 